\title{
Right Kidney
}

National Cancer Institute

\section{Source}

National Cancer Institute. Right Kidney. NCI Thesaurus. Code C34005.

A bean-shaped retroperitoneal org an situated below the diaphragm and posterior to the liver. 